\title{
O TEMA DE KÔJIN DE SÔSEKI NATSUME
}

Akira Ikari*

Desde a sua obra Gubijinsô, "A papoula", parece que Sôseki Natsu$\mathrm{me}^{\star *}$ prepara uma trama secundária ao conceber um romance genuíno, tendo em vista despertar o interesse do leitor.

Isso pode ter ocorrido pelo fato de muitas de suas obras terem sido publicadas, em série, em jornal, mas a razão mais forte deve repousar na visão literária fundamental do autor. Sôseki não apreciava os meios que atraiam o leitor com atrativos baratos que possuiam deslizes, preferindo enfrentar cara a cara, perseverantemente, a vida e o homem. Por esse motivo, ele adotou os meios narrativos tradicionais da literatura ocidental e buscou 0 romance autêntico que possuisse uma estrutura sólida. Desde sanshirô, "Sanshirô", Sorekara, "E depois", até Meian, "Luz e sombra", todas as suas obras são concebidas tendo em vista esse objetivo.

Acreditamos que por causa desta visão novelística básica, Sôseki prepara uma trama secundária e arma uma estrutura sólida e minuciosa.

Essa trama secundária avança de Sorekara para Mon, "O portão", torna-se complicada, gradativamente, e acaba se diluindo dentro da obra. Chega-se ao ponto de o leitor ver-se impossibilitado de prever a estruturação do todo ou as relações de causa e efeito dos acontecimentos, nos capítulos iniciais.

Em Sanshirô, a técnica da trama secundária não é tão sofisticada. Não passa de uma leve complicação dos protagonistas que cercam a personagem Mineko, especialmente a sua relação com Nonomiya.

Em Sorekara, isso se torna razoavelmente complexo. Está colocado da seguinte forma: no capítulo II, Daisuke diz que "Devido a um certo acontecimento, não tinha como me esquecer de Hiraoka", mas não há nenhuma explicação referente a esse "certo acontecimento", deixando o leitor na ex- 
pectativa; somente quando avançado o capítulo VII, surgem Suganuma e a sua irmã mais nova, Michiyo, tornando clara a relação entre Daisuke e Hiraoka. Ou seja, o mistério da trama secundária mantem-se até a terça parte dos dezessete capitulos totais.

Em Mon, essa tendência se intensifica e o segredo de Sôsuke e Oyone só é revelado depois da metade da obra. Isto é, somente no capítulo XIV, no total de vinte e três, surge, pela primeira vez, a personagem Yasui e ficam esclarecidas as particularidades referentes ao triângulo amoroso envolvendo Yasui, Sôsuke e Oyone.

Parece que Sôseki dedicou maior atenção ao suspense em Mon do que em Sorekara. E na trilogia, Sanshirô, Sorekara e Mon, esta técnica da trama secundária revela-se extremamente eficaz e contribui sobremaneira para o sucesso da mesma.

Com relação a Higansugimade, "Até depois do equinócio da primavera", a primeira obra escrita após o grave problema de saúde*, Sôseki utilizou-se intensamente da trama secundária, no decorrer de toda a obra. Desde o primeiro capítulo, ele adotou a técnica onde o objetivo principal da obra estava no "desvendamento de um segredo" Trata-se de uma técnica semelhante à do romance policial.

Em Higansugimade, o leitor segue um casal misterioso, juntamente com a personagem principal, o jovem Keitarô Tagawa, e, atraído pelo interesse de desvendar esse mistério, prossegue a sua leitura, mas quando no capítulo da primeira metade, intitulado "Relatório", o mistério é solucionado, ele perde o interesse. Originalmente, Sôseki preparou depois disso, dois capítulos, por ele considerados de peso, intitulados "História de Sunaga" e "História de Matsumoto", de modo que a trama secundária da primeira parte desempenha, digamos, o papel de uma introdução que incita o interesse do leitor. Trata-se, provavelmente, da mesma técnica utilizada pelo escritor inglês Stevenson, mas em Higansugimade a trama secundária não foi adotada necessariamente como uma estrutura que abrange toda a obra.

A técnica da trama secundária de Sôseki desenvolveu-se a tal ponto em Kôjin, "O viandante", que acabou ocultando-se dentro da obra. Nessa técnica, o mistério da trama secundária deixa, às vezes, entrever parte de si na superfície da obra, outras vezes, desaparece por completo, e o desvendamento não ocorre até o fim. Tem justamente o efeito causado pelo apare- 
cimento de um cardume de peixes no mar, que surge, de tempos em tempos, na superfície da água, assusta os que o vêem e some novamente para o fundo do mar. $\mathrm{O}$ autor utilizou em Kôjin a técnica mais difícil da trama secundária.

Kôjin é um romance que apresenta uma razoável dificuldade de compreensão. Trata-se de uma obra que apresenta partes extremamente obscuras, como a relaçāo entre as personagens Ichirô, Jirô e Onao, o significado da parte introdutória "Amigo", o significado dos acontecimentos que envolvem a personagem Misawa. Conforme as palavras de Tsutomu Nishigaki:

Acredita-se que, por ser complexa e obscura, restam problemas insolúveis até hoje.(1)

Desta feita, ao examinarmos a visão naturalista de Sôseki e a partir da sua apreciação concernentes às obras de Maupassant(2), pudemos identificar alguns pontos que nos parecem significativos no que se refere às obras Pierre e Jean e Kôjin(3). Já tivemos a oportunidade de escrever detalhadamente sobre essa questão em outros artigos, mas, em suma, ao verificarmos as impressōes e os comentários deixados por Sôseki nas guardas das Obras Completas de Maupassant, da sua coleção particular, a que temos acesso atualmente, somos de supor que Sôseki ficou deveras impressionado com a leitura de Pierre e Jean e, fez uso desta obra na concepção de Kôjin.

A particularidade de Kôjin reside provavelmente no fato de não solucionar, até o fim, o mistério da trama secundária. $O$ autor manteve o tema em segredo, até o fim, não o trouxe à tona e expressou-o de uma maneira indireta. Conseqüentemente, Kôjin tornou-se uma obra obscura para o leitor.

Como exporemos mais adiante, o tema seria "o amor de Onao por Jirô" Onao amava Jirô. Aí residia o mistério da trama secundária. Não obstante, devido a várias circunstâncias, evitou-se escrever abertamente sobre isso. Desse modo, sem escrever claramente, Sôseki encontrou um modo de fazer o leitor compreender isso nas entrelinhas. A dificuldade da trama secundária do autor estava exatamente aí.

A primeira chave para desvendar Kôjin foi encontrada na passagem 20, do capítulo III, intitulado "Depois da volta" Estava dentro do diálogo entre Jirô e sua mãe.

(1) NISHIGAKI, Tsutomu - "Kójin - A luta entre o ego e o amor" (Kôjin - Jigato aino sókoku). In: Natsume Sóseki hikkei, Tôkyó, Gakutôsha, 1980.

(2) IKARI, Akira - "Sóseki Natsume e o naturalismo - Com relação à apreciação de Maupassant" (Natsume Sósekito shizenshugi - Mópassanno hyokao megutte). In: Niigata Daigaku Kokubun Gakkaishi, Niigata, 28, 1985.

(3) IKARI, Akira - "O enredo de Kójin e a obra Pierre e Jean" (Kojinno kósóto Piêruto Jam). In: Nihon Kindai Bungaku, 33, out. 1985. 
Disse (a mãe): "Jirô, o dia em que você nos deixar, a casa ficará extremamente triste e vazia, mas encontre logo uma boa esposa e arranje um jeito de se tornar independente." Para mim, ficou claro que, por trás das palavras de mamãe, ela quis dizer que se eu constituisse uma nova familia e me tornasse independente, melhoraria um pouco 0 humor do meu irmão mais velho. (...)

"Estou perante a senhora, mas, trata-se da relação entre o mano e sua esposa. Existem ai diversas circunstâncias complexas e, pelo fato de sermos, de certa maneira, antigos conhecidos ${ }^{\star}$, fico constrangido em lhe causar preocupação, mas (...)"

Pode ser que existam outras chaves para a solução do mistério. No entanto, a nosso ver atual, no diálogo entre Jirô e sua mãe, citado acima, Sôseki ocultava uma importante trama secundária. A sua localização quase coincide com a de Mon, ou seja, situa-se um pouco depois da metade da obra.

A chave para a solução do mistério baseia-se nas seguintes condiçōes: a mãe desconfia, no intimo, da relação entre Jirô e Onao; Jirô e Onao já se conheciam anteriormente e a situação é tal que não seria estranho se o amor nascesse entre os dois. $O$ fato de Jirô e Onao já se conhecerem anteriormente constituia o primeiro passo da trama secundária de Sôseki.

Não há nenhuma explicação a respeito das circunstâncias que envolvem o casamento de Onao e Ichirô. Entretanto, Onao e Jirô já haviam se encontrado antes do casamento e, embora não haja nenhuma explicação, provavelmente os dois eram conhecidos, haviam se encontrado algumas vezes e estavam a par do temperamento um do outro. Onao conhecia o temperamento franco e tranqüilo de Jirô. Existia, entre os dois, um sutil intercâmbio espiritual. Se nos é permitido imaginar, pode ser que Onao tivesse interesse em Jirô e casou-se com Ichirô por ser ele o seu irmão mais velho.

$E$, tanto Ichirô como a mãe sabem das circunstâncias que envolvem o relacionamento anterior dos dois. Sabem do antigo relacionamento do qual pode surgir 0 amor entre os dois. $O$ ciúme de lchirô e as suspeitas temerosas da mãe advêm desse conhecimento. Entre Jirô e Onao existia, desde antigamente, uma corrente intima e pode ser que Onao tivesse interesse por Jirô, desde essa época. No comportamento e nos gestos de Onao para com Jirô sente-se, agora, uma intimidade particular que provoca na mãe um sentimento de apreensão.

A segunda chave está no final do capítulo "Amigo", onde Misawa é idolatrado por uma jovem com distúrbios mentais. A jovem começou a demonstrar essa anomalia, depois de um casamento infeliz que terminou em separação, mas foi recolhida na casa de Misawa a quem passa a idolatrar. 
Quando ele saía de casa, a jovem que infalivelmente o acompanhava até 0 hall, fitava-o com os seus olhos negros como se quisesse denunciar a sua solidão. Cada vez que isso acontecia, Misawa sentia "como se ela se agarrasse na sua manga e Ihe implorasse: por favor, ajude-me, pois não agüento viver assim tão só!" ("Amigo", passagem 33). Este episódio antecipa o importante tema da segunda metade da obra.

Como exporemos mais adiante, Jirô é amado e idolatrado por Onao e ele sofre por isso, o que se assemelha ao episódio citado acima, onde Misawa é idolatrado pela jovem desequilibrada.

Na passagem 23 do capítulo "Depois da volta", Misawa adverte Jirô, dizendo que ele está cometendo um erro, ao ficar tanto tempo perto de Onao e, após mostrar a secreta idolatria de Onao por Jirô, o autor dá a entender que, no caso de Misawa, não existia motivo de preocupação, pois a mulher que lhe nutria paixão era uma desequilibrada e, além disso, já estava morta, mas no caso de Jirô, tudo leva a crer que haverá complicaçōes. $O$ autor narrava claramente, aqui, a similaridade entre o amor de Misawa e 0 de Jirô. A proposta estava aqui.

Misawa sofre, sendo idolatrado pela jovem com problemas mentais, não obstante, sente também compaixão e amor por ela. Também Jirô sofre por causa do secreto amor da cunhada e Onao, por sua vez, considera-se "mera sombra de si própria" (o que poderia ser interpietado também como uma espécie de anormalidade psíquica). Jirô compadece-se da dor de Onao e não pode deixar de sentir esse amor ilícito - assim, o sofrimento de Misawa e Jirô são similares.

Na passagem 4 do capítulo "Angústia", há uma cena em que Onao vai à pensão de Jirô e queixa-se da sua situação. Onao procura provavelmente, aqui, o auxílio e o amor de Jirô. Por trás deste apelo comovente Jirô sente, como se tivesse levado um choque elétrico, a incomensurável força feminina. Ele sente, como se tivesse levado um choque, intuitivamente, a seriedade do apelo de Onao e que, por trás deste apelo, ela estava Ihe declarando o seu amor.

Após o apelo comovente de Onao, Jirô passa um bom tempo "sendo perseguido constantemente pelo fantasma da cunhada." ("Angústia", passagem 6). Isto equivale exatamente à perseguição empreendida pela jovem desequilibrada a Misawa, no capítulo "Amigo"

Em outras palavras, os dois jovens são amados e idolatrados, respectivamente, por uma mulher impossibilitada de se casar e pela própria cunhada, e sofrem por causa disso - esta deve ser a proposta de Kôjin. $\mathrm{O}$ au- 
tor Sôseki traçou desde o início o seu plano baseado nesse propósito e, deixou oculta a trama secundária.

Desse modo, o significado e a posição do capítulo "Amigo", dentro da obra Kôjin, ficam claros.

A técnica da trama secundária de Sôseki é realmente perspicaz e está colocada num local profundo que não pode ser detectado numa leitura superficial. Como exporemos mais adiante, o motivo para tal atitude estava, provavelmente, relacionado com o fato de existir no tema restriçōes sociais ou problemas de fundo moral. Somos de opinião que, pelo fato de o próprio assunto, ou seja, a vida intima de um casal, ser de difícil abordagem, isso tornou também a trama secundária mais complexa.

A cena que se refere à peça do teatro Nô (passagem 13 em diante), do capítulo "Depois da volta", contém também uma "sugestão" extremamente importante. Essa importância já havia sido apontada por Toshio Hiraoka(4). Existem aqui episódios bastante significativos que funcionam como trama secundária, tais como o verdadeiro caráter de uma mulher que esconde um segredo intimo ou os problemas sexuais de um casal.

Baseado na obra Pierre e Jean, Sôseki preparou a trama secundária, estabelecendo o tema central na discórdia que envolve os irmãos, Ichirô e Jirô, com relação a Onao. No entanto, como veremos mais adiante, devido ao ponto de vista moral do autor e também por outros motivos, o amor ilícito não surge à tona por nenhum momento, e foi adotada uma atitude em que descriçōes diretas foram evitadas.

Jirô e Onao eram conhecidos antigos (passagem 20, capítulo "Depois da volta") e, provavelmente, Onao sentia-se atraida pelo tranqüilo e gentil Jirô. Após o casamento, Onao acha repulsivo o sombrio e nervoso Ichirô e mostra-se "indiferente e fria" (passagem 14, capitulo "Irmão mais velho") com o marido. Por outro lado, o sentimento de carinho que tinha por Jirô transforma-se em amor, mas como Onao o esconde, Jirô não o percebe. $O$ marido Ichirô, no entanto, percebera intuitivamente o amor da esposa pelo irmão mais novo. $O$ ciúme de Ichirô cresce cada vez mais, até culminar no caso de Wakayama.

(4) HIRAOKA, Toshio - "Kojjin e suas cercanias" (Kójinto sono shûhen). In: Sóseki josetsu, Tókyó, Hanawashobo, 1976. 
Ichirô diz repentinamente a Jirô:

"Onao está apaixonada por você, não?"

(passagem 18, capftulo "Irmão mais velho")

Jirô enrubesce. Isso porque ele não se sentia completamente inocente. Ichirô confessa o seu sofrimento "por ter se casado com uma mulher que não possui nem espírito nem alma." (Passagem 20, "Irmão mais velho"). E pedeIhe que teste os sentimentos de Onao.

Depois disso, temos o caso que se refere à ida para Wakayama. Onao queixa-se a Jirô, falando sobre o desentendimento com Ichirô e chora, dizendo que ela não passa de "mera sombra de si própria" O sentimento de Jirô vai, pouco a pouco, transformando-se de compaixão em amor. Ao ver as lágrimas de Onao, sente uma inexplicável compaixão e o seu desejo é de Ihe tomar as mãos e chorar junto. Sente vontade de enxugar as lágrimas de Onao.

Devido à tempestade, vêem-se obrigados a pousar juntos no local. Ai também, o autor preparou uma trama secundária bastante forçada.

Se Onao não gostasse de Jirô, provavelmente não iria a Wakayama com ele. Além disso, se Onao não amasse Jirô, por mais que fosse uma noite tempestuosa, rejeitaria terminantemente aquele modo de pernoite. Isso seria o senso comum. Ademais, o fato de Sôseki, dono de um sentimento incomum de moralidade, ter criado uma noite como aquela, é bastante significativo.

Os dois dormem, lado a lado, na escuridão da tempestade. Onao está até maquiada discretamente, e embora indiretamente, diz que não se importa com o que possa acontecer e chega a desafiar Jirô a se jogarem juntos ao mar. Esse trecho da obra poderia ser considerado como uma espécie de prelúdio desse amor. É uma cena que podemos chamar de adultério espiritual, onde conforme coloca Yoshimi Hashimoto:

Os dois não podem ser considerados totalmente inocentes.(5)

Jirô vacila e, mesmo "depois da volta", as informaçōes para o irmão tornam-se relutantes. $\mathrm{O}$ amor de Onao estava enrodilhado no corpo de Jirô como "uma macia cobra verde" * A mãe pressente a relação entre Onao e

(5) HASHIMOTO, Yoshimi - "Sobre Kójin" (Kojinnitsuite). In: Kokugoto kokubungaku, Tôkyó, Shibundô, jul. 1967.

Aodaishó, elaphe climacophora, a maior das cobras não-peçonhentas nativas do Japão, de coloração esverdeada e que alcançam 1,5 a 2 metros de comprimento. (N. da T.) 
Jirô e aprofunda as suas suspeitas. (Passagem 42.) Ela mantivera-se discretamente vigilante, mesmo depois da volta de Wakayama.

E durante o desenvolvimento, chegamos à importante cena referente à peça do teatro Nô.

A idéia principal de Kôjin está oculta nessa cena. A apreensão torna-se dificil pois, durante toda a obra, o escrever de Sôseki chega a se manter carregado e cauteloso, mas nessa cena está subentendida toda a complicada situação entre os dois irmãos e Onao.

A partir da cena referente à peça Kagekiyo, inicia-se a história de uma mulher cega que, guardando durante mais de vinte anos a relação que tivera com o seu primeiro amor, confessa que "o que mais a angustia é o fato de não poder saber o que os outros pensam" Ouvindo isso, o imão mais velho fica com "a cor dos olhos que denota tensão nervosa" e Onao deixa escapar um sorriso irônico. Isso porque Ichirô sofre por não conseguir ler seus pensamentos e Onao está terminantemente decidida a não lhe abrir o coração. Esse sorriso irônico reflete também a personalidade de Onao, aparentemente submissa, mas na realidade, determinada, a ponto de não voltar, absolutamente, atrás em suas decisões.

E também Jirô, envolvido pelo clima de mal-estar, possível de ser interpretado como ódio mútuo entre os dois, não pôde deixar de se conscientizar desse triângulo amoroso, para onde ele próprio "estava sendo arrastado"

Ainda quando Ichirô explana sobre a teoria sexual, baseada no evolucionismo, e diz que, uma vez ocorrida a relação, a mulher torna-se ativa, Onao mostra um leve menosprezo, comentando: "Que história estranha, não?" Isso poderia estar insinuando que Onao não tomara, anteriormente, a inciativa sexual com relação ao marido ou ainda que a relação entre os dois já arrefecera completamente. lichirô adquire "uma expressão desagradável que não se mostra às visitas" O fato de o autor ter introduzido, aqui, o caso da vida conjugal é bastante significativo como uma trama secundária.

Há também a fala da visita que diz: "A mulher é um ser obstinado e é capaz de guardar um segredo durante mais de vinte anos, dentro do peito." Isso está "sugerindo" que a insatisfação de Onao com relação ao marido e o seu amor por Jirô encontram-se ocultos, bem no fundo do seu peito.

A dificuldade maior do autor deve ter sido com relação ao amor de Onao. Ocultar a sete chaves, guardar dentro do peito como um segredo, conseqüentemente não o expressar absolutamente em palavras, não obstante, deixar oculto no fundo como um "realce secreto", ai estava, na nossa opiniāo, o grande sofrimento de Sôseki. 
Os ciúmes e as angústias de Ichirô são descritos abertamente como no caso de Pierre, de Maupassant, mas o amor de Onao por Jirô e o posterior temor de Jirô não estão patentes e são descritos de modo indireto. Além disso, a dificuldade da narrativa estava no fato de o triângulo amoroso constituir-se no tema. $O$ fato de Sôseki ter escrito na sua carta, datada de $1^{\circ}$ de dezembro de 1912, endereçada a Nakamura:

"O sofrimento inútil tentando dispor vividamente algo complexo ou o aborrecimento que advém no fim, etc..."

parece se referir a essa dificuldade.

\section{O amor de Onao era o tema secreto.}

Em Pierre e Jean, a mãe confessa finalmente um amor que vinha escondendo há mais de vinte anos por um homem. Sôseki também faz com que Onao confesse, por seu lado, o seu amor por Jirô e este, ao tomar conhecimento desse amor, teme pela culpa de um amor ilícito - esse arranjo era a sua intençăo final.

Cultivando no íntimo do seu âmago o seu interesse por Jirô, Onao faz com que esse interesse vá adquirindo proporçōes maiores; Jirô que vai, pouco a pouco, sendo conscientizado do amor de Onao e Ichirô, que percebendo essa relação entre os dois, faz explodir a sua ira - não obstante tudo isso, a técnica da trama secundária de Sôseki é duplamente complexa, não deixando entrever absolutamente nada na superfície e só se expressa através de frases extremamente indiretas.

Sôseki só se expressa através de explicações e frases obscuras como nas seguintes passagens: na passagem 25 do capítulo "Depois da volta", quando Jirô pensa em sair de casa e mudar-se para uma pensão, Onao pergunta a Jirô se gostaria que the procurasse uma esposa e, "mostrando um sorriso que denotava desprezo ou zombaria, nos dois cantos dos seus finos lábios, e andando propositadamente com passos ruidosos, desapareceu na direção da sala"; na passagem 27, quando Jirô relata a sua intenção de ir morar numa pensão, lchirô lhe pergunta se ele vai sozinho.

No entanto, o tema central de Kôjin era "o amor de Onao" O autor tinha como intenção inicial trazer no fim a confissão de Onao. Entretanto, as condiçōes sociais e morais do Japão e o senso ético de Sôseki não permitiram que um amor ilícito como esse fosse expresso abertamente.

Foi Toshihiko Izu quem fez alusão à "estrutura dupla do mundo do sıgnificado explícito da palavra e do mundo do significado implícito."(6) Isso não

(6) IZU, Toshihiko - "A premissa do estudo de Kôjin" (Kójinronno zentei). In: Nihon bungaku, Tókyó, mar. 1969. 
era devido à técnica narrativa. Havia no tema central uma restrição social e um impedimento moral. $O$ autor possuia uma consciência de bons costumes. Por esse motivo, ele tinha que fazer o leitor compreender isso sem 0 expressar em palavras. $E$ por isso mesmo, talvez tenha sido obrigado a se utilizar da técnica da trama secundária tão complexa como essa.

A personalidade de Onao é descrita como sendo de natureza fria, de aparente fragilidade, e o seu amor por Jirô é escondido por essa personalidade, mas, no íntimo, ela está ardendo em chamas. Para que o amor de Onao fosse compreendido como tal, Sôseki havia preparado meticulosamente, aqui e ali, episódios enigmáticos e frases obscuras como tramas secundárias.

Também o episódio de Misawa e a jovem desequilibrada, citado anteriormente, serviu para mostrar, posteriormente, o comovente amor secreto de Onao e, mesmo o amor entre Paulo e Francisca da Divina Comédia de Dante, citado na obra, era o próprio retrado do amor entre Jirô e Onao. Ichirô traz à tona todo o seu ciúme, pois acreditava que, provavelmente, Jirô, assim como Paulo, aceitaria o amor de Onao, e levado pelo sentimento natural, pretendia tornar-se "o vencedor eterno"

Acreditamos que os demais trechos com significado obscuro espalhados dentro de Kôjin possam, até certo ponto, ser interpretados seguindo-se essa linha, mas mesmo assim, o escrever de Sôseki era de prudência. Sôseki sofreu duras penas para tomar real, o tanto quanto possivel, as particularidades da psicologia de Onao, até que ela chegasse à sua confissão. A partir do trecho em que Jirô sai de casa e vai morar em uma pensão, o escrever de Sôseki torna-se ainda mais cauteloso.

Por essa razão, parece que Sôseki pretendia concluir o capitulo "Depois da volta" com cerca de trinta passagens (hipótese de Toyotaka Komiya), mas alongou-se mais do que o esperado, e devido também à sua enfermidade, foi interrompido na passagem 38.

Recuperado de sua enfermidade, ele publicou a continuação intitulada "Angústia", depois de cinco meses, e a partir da passagem 1 é abordada a cena em questão.

Numa noite do início da primavera, Onao visita pela primeira vez a pensão de Jirô. Sentados frente a frente em volta de um braseiro, Jirô sente uma "perplexidade inquietante" e se sucumbe "diante do enigmático sorriso" de Onao, semelhante ao de Mona Lisa. 
Ao ser indagado por Onao o motivo pelo qual não visitava a casa dos pais, Jirô fica sem resposta - a razão estava em que ele temia encontrar-se com Onao e não imaginava que ela the indagasse sobre isso. "Você é por demais audaciosa", "Eu, no final das contas, era um covarde" - pensou Jirô, sufocando o seu próprio amor. Jirô só consegue Ihe responder. "Estou com vontade de viajar para o exterior daqui a algum tempo" Jirô sente até que a testa e a cor das faces de Onao, que se encontra diante dele, são ofuscantes. Onao queixa-se de que a sua relação com Ichirô está piorando cada vez mais. Ela nunca se abrira dessa maneira antes. Jirô sentiu uma ardência como se o "eu-covarde" tomasse repentinamente um banho de ácido. Onao estava procurando em Jirô algum tipo de auxílio.

E Onao queixa-se ainda, dizendo que o homem pode sair voando para qualquer lugar, mas "eu sou exatamente como uma planta de vaso enraizada pelas mãos dos pais" e, "enquanto não chegar alguém para me tirar do lugar, não há outro jeito senão permanecer imóvel até murchar."

Não haveria, provavelmente, erro de nossa parte se considerarmos esse trecho como o que corresponde à declaração de amor feita por Onao a Jirô. Essa era a discreta confissão de amor da mulher japonesa, nos tempos antigos. E a pena do autor só podia expressá-la nesses termos.

Yoshimi Hashimoto refere-se a essa sutileza nos seguintes termos:

Tem-se a impressão de que se atingiu o clímax da história de ambos. Onao, discreta em tudo e sempre reservada, abre-se totalmente para Jirô. Algo que se assemelha à "beleza da infidelidade" paira no ar, de maneira comovente e bela.(7)

Depois disso, Jirô é permanentemente atormentado pela visão de Onao. Surgem-lhe vividamente a imagem da sua testa, das suas faces e até da cor dos seus lábios e Jirô "é perseguido pelo fantasma da cunhada" Jirô tinha percebido a declaração de amor de Onao. Entretanto, acaba por rejeitá-la e "não lhe estende a mão da salvação" A personagem Daisuke de Sorekara aceita a "vontade divina", vive o amor natural e recebe a punição da sociedade, mas Jirô dá as costas para a voz do instinto e cumpre a ordem social.

A intenção inicial do autor seria, provavelmente, depois disso, de concluir ou com uma proposta de casamento trazida para Jirô ou com a partida de Jirô para o exterior, após recusar a proposta. Parece que isso estava mais ou menos estruturado antes da interrupção, devido à sua doença, segundo o artigo "Sobre a continuação de Kôjin", publicado pelo autor no jornal Asahi.

(7) HASHIMOTO, Yoshimi - "Sobre Kojin (Köjinnitsuite). In: Kokugoto Kokubungaku, Tókyó, Shibundo", jul. 1967 
Isso, no entanto, deve ter sido alterado na medida em que, juntamente com a mudança de opinião ocorrida durante a enfermidade, houve 0 acréscimo de uma narrativa sob o ponto de vista de lchirô, como que descrevendo o sofrimento sob o prisma de um intelectual.

Desde antes, no intervalo entre a fase anterior à doença e o capítulo "Angústia", escrito após o restabelecimento, a mudança do tema havia sido apontado.

Devido ao conteúdo significativo da "Carta do Sr. H", atribuiu-se a ela um significado relevante no que tange à pesquisa geral de Sôseki, e a ênfase da investigaçāo referente à obra Kôjin passou a se voltar para essa direção. A partir desse ponto de vista, o tema "amor de Onao" tinha sido negligenciado - não seria esse o esboço da história da pesquisa de Kôjin?

De um modo geral, no caso de Kôjin, a técnica da trama secundária de Sôseki possuía um senão pelo excesso de complexidade. Pelo fato de tratar sobre um assunto, como o problema do sexo, de difícil abordagem, 0 autor hesitou em escrever abertamente. Devido à restrição moral e social ou à consciência de bons costumes, não pôde deixar de "reprimir a sua pena"

Por esse motivo, viu-se inclinado a abusar da técnica da trama secundária. Ultrapassando, entretanto, esses problemas, a obra Kôjin é realmente uma obra brilhante. Quanto mais complexa a trama secundária, não poderia se considerar, dependendo do ponto de vista, que se trata de uma obra magnífica onde Sôseki demonstrou toda a sua genialidade? 